\title{
Age-related differences in brain electrical activity during extended continuous face recognition in younger children, older children, and adults
}

\author{
Jan W. Van Strien ${ }^{1}$ \\ Johanna C. Glimmerveen ${ }^{2}$ \\ Ingmar H.A. Franken ${ }^{1}$ \\ Vanessa E.G. Martens ${ }^{3}$ \\ Eveline A. de Bruin ${ }^{3}$
}

\footnotetext{
${ }^{1}$ Institute of Psychology, Faculty of Social Sciences, Erasmus University Rotterdam, The Netherlands

${ }^{2}$ School of Social and Behavioral Sciences, Tilburg University, The Netherlands

${ }^{3}$ Sensation, Perception and Behaviour, Unilever R\&D Vlaardingen, The Netherlands
} 


\begin{abstract}
To examine the development of recognition memory in primary-school children, 36 healthy younger children (8-9 years old) and 36 healthy older children (11-12 years old) participated in an ERP study with an extended continuous face recognition task (study 1). Each face of a series of 30 faces was shown randomly for six times interspersed with distracter faces. The children were required to make old vs. new decisions. Older children responded faster than younger children, but younger children exhibited a steeper decrease in latencies across the five repetitions. Older children exhibited better accuracy for new faces, but there were no age differences in recognition accuracy for repeated faces. For the N2, N400 and late positive complex (LPC), we analyzed the old/new effects (repetition 1 vs. new presentation) and the extended repetition effects (repetitions 1 through 5). Compared to older children, younger children exhibited larger frontocentral N2 and N400 old/new effects. For extended face repetitions, negativity of the N2 and N400 decreased in a linear fashion in both age groups. For the LPC, an ERP component thought to reflect recollection, no significant old/new or extended repetition effects were found. Employing the same face recognition paradigm in 20 adults (study 2), we found a significant $\mathrm{N} 400 \mathrm{old} /$ new effect at lateral frontal sites and a significant LPC repetition effect at parietal sites, with LPC amplitudes increasing linearly with the number of repetitions. This study clearly demonstrates differential developmental courses for the N400 and LPC pertaining to recognition memory for faces. It is concluded that face recognition in children is mediated by early and probably more automatic than conscious recognition processes. In adults, the LPC extended repetition effect indicates that adult face recognition memory is related to a conscious and graded recollection process rather than to an automatic recognition process.
\end{abstract}

Key words: Event-related potentials; Old/new effect; P2; N400; Late positive complex (LPC); Face recognition; Memory; Child development; extended continuous repetition 


\section{Introduction}

Behavioral research has demonstrated that recognition memory improves from infancy into young adulthood (e.g., Billingsley, Smith, \& McAndrews, 2002; Cycowicz, Friedman, Snodgrass, \& Duff, 2001). It has been suggested that the increase of recognition memory proficiency with age is associated with differential developmental trajectories of two types of retrieval processes: a fast familiarity process and a slower recollection process. With recollection, the context in which information is presented is also remembered, while with familiarity it is not (e.g., Curran, Tepe, \& Piatt, 2006). Better recollection is associated with age-related increases of activations in the dorsolateral prefrontal cortex (Ofen et al., 2007). As a consequence of the longer maturational course of the frontal cortex, recollection may display a longer developmental trajectory than familiarity (Cycowicz, 2000). Familiarity is usually thought to be a form of explicit memory (see Rugg et al., 1998). People 'know' they have seen a stimulus before but can not retrieve the details of the context of the first stimulus presentation. In research, the dissociation of familiarity and recollection processes is typically observed with specific source memory or 'remember/know' paradigms.

Numerous event-related potential (ERP) studies have supported a dual-process account of recognition memory. When participants have to recognize studied items from a list of targets and distracters, the correct identification of studied items is associated with an increased positivity of the ERP waveform starting about $300 \mathrm{~ms}$ after stimulus onset. This ERP old/new effect typically comprises an early mid-frontal component (N400 old/new effect, time window 300 to $500 \mathrm{~ms}$ ) that is thought to reflect familiarity and a later parietal component (late positive potential - LPC old/new effect, time window 500 to $800 \mathrm{~ms}$ ) that is thought to reflect recollection (Curran et al., 2006; Rugg \& Curran, 2007).

With a continuous recognition paradigm, a similar dissociation of the early and late ERP old/new effect has been established. Since in this paradigm old and new items are intermixed, the early old/new effect may be akin to a more implicit recognition process that can still be dissociated from a slower, explicit recollection process (Van Strien, Glimmerveen, Martens, \& De Bruin, 2009; Van Strien, Hagenbeek, Stam, Rombouts, \& Barkhof, 2005). Using an extended continuous-word-recognition paradigm in which each item was repeated nine times, Van Strien et al. (2005) demonstrated that the positivity of the LPC increased linearly with the number of repetitions. By contrast, the early N400 old/new effect was not affected by the number of 
repetitions. These results suggested that the LPC old/new effect reflects a graded recollection process that depends on the strength of the memory trace, whereas the early N400 old/new effect reflects an automatic matching process that is not dependent on memory strength. The N400 old/new effect in the study by Van Strien et al. was observed at mid-parietal rather than midfrontal electrode positions. In another continuous word-recognition study, Van Strien et al. (2007) found that this parietal $\mathrm{N} 400 \mathrm{old} /$ new effect was much larger with immediate than with delayed repetitions. It is therefore likely that with continuous recognition, the N400 old/new effect reflects implicit memory rather than familiarity. This is in concordance with Rugg and colleagues (Rugg \& Curran, 2007; Rugg et al., 1998), who also proposed that the early parietal old/new effect is a neural correlate of implicit memory processes.

Earlier old/new effects than the $\mathrm{N} 400$ have also been observed in old/new paradigms. With continuous face recognition, Guillem et al. (Guillem, Bicu, \& Debruille, 2001) found a N2 old/new effect around $246 \mathrm{~ms}$, with the N2 going more positive to old than new items. Van Strien et al. (Van Strien, Langeslag, Strekalova, Gootjes, \& Franken, 2009) found a similar N2 effect in the 200-300 ms time window with continuous picture recognition. The early and later ERP old/new effects may reflect the temporal and spatial course of consecutive recognition processes such as perceptual matching/priming, familiarity, and recollection (see Ally \& Budson, 2007, for a proposed EEG model).

As the adult ERP studies demonstrated different neural correlates for an early implicit recognition process and a later recollection process, developmental studies have provided some evidence for a differential development of these correlates. Czernochowski et al. (2005) found early frontal old/new effects for pictures in adults only, and later parietal old/new effects in younger and older children, and adults. They concluded that children predominantly rely on recollection, even though the prefrontal memory processes are not fully matured. Employing an extended continuous word recognition task in which each word was repeated five times, Van Strien et al. (Van Strien, Glimmerveen et al., 2009) found a much stronger N400 old/new effect in 11- and 12-year-old children than in 8- and 9-year-old children. Both age groups exhibited comparable LPC old/new and extended repetition effects. This LPC old/new effect suggested that recollection plays a substantial role in word recognition memory of both younger and older children, while the $\mathrm{N} 400$ old/new effect suggested that additional semantic representations may be available for more automatic word recognition memory in older children. Several other ERP 
studies found no developmental trends for the early and late old/new effects (Berman, Friedman, \& Cramer, 1990; Cycowicz, Friedman, \& Duff, 2003).

Because recognition memory will depend on the development of a particular cognitive domain, the developmental ERP trends could be affected by the type of stimuli that is used. For instance, the early and late old/new effects for word recognition memory may be connected with the development of other verbal skills such as reading or semantic processing (Van Strien, Glimmerveen et al., 2009), while old/new effects for face recognition memory may be associated with the development of facial processing abilities.

\section{Face recognition}

Face recognition is an important type of recognition memory, especially in social interactions. Although even very young children are capable of recognizing their own mother's face (De Haan \& Nelson, 1997; Ellis, 1992), face recognition in children is relatively poor when compared to face recognition in adults. The gradual increase in face recognition performance with age is traditionally thought to be due to increasing configural processing abilities (a view dating back to Diamond \& Carey, 1977), which allow adults to better grasp the relationships between facial features. Recent research however, suggests that the configural processing abilities already are mature in four- to seven-year-old children (Crookes \& McKone, 2009; de Heering, Houthuys, \& Rossion, 2007) and that the psychophysiological correlates of face-sensitive

perceptual processes do not change from 4 years to adulthood (Kuefner, de Heering, Jacques, Palmero-Soler, \& Rossion, 2009).

Only few ERP studies investigated the development of face recognition memory in children. Itier and Taylor (2004) presented upright, inverted and contrast-reversed faces to 8-16 year old children. One-third of the faces was repeated immediately or after one intervening face. Old/new effects were found in the $250-500 \mathrm{~ms}$ time window and were not influenced by age or face types. The old/new effect was larger for immediately repeated faces than for 1-lag repeated faces (cf. Van Strien et al., 2007). The authors concluded that in all age groups a comparable general working memory system was involved. The steady improvement in face recognition from 8 to 16 years for both upright and inverted faces led Itier and Taylor to conclude that the increasing face recognition performance with increasing age was driven by general memory improvements rather than by increased configural processing. 
In another continuous-recognition ERP study with words and faces, Hepworth et al. (2001) found a late parietal P3 old/new effect (peaking around $550 \mathrm{~ms}$ ) in 11-14 year old children, which was significantly larger for words than for faces over the left parietal region. Further, they found increased latencies and decreased amplitudes for the early ERP components to faces compared to words. The authors concluded that their findings demonstrated that for 1114 year olds, the early processing of faces is more difficult than the early processing of words, the latter being comparable to adults.

As the results of Itier and Taylor (2004) imply a role of early automatic processes and the results of Hepworth et al. (2001) imply a role of later recollection processes in face recognition memory of school-aged children, the question arises whether the N400 old/new effect and the LPC old/new effect will show different or similar developmental trajectories.

\section{The present study}

Here we examined developmental changes in face recognition memory by comparing processing and performance in 8-9-year-old and 11-12-year-old children on an extended continuous face recognition paradigm (Study 1). To provide a context for the developmental findings, we also examined an adult sample in a separate study (Study 2). Because the research settings and testing conditions between children and adults were different, the results for the adult sample will be analyzed and reported separately.

This is the first ERP study to apply an extended continuous face recognition task in school-aged children and adults. Previous studies with an extended continuous word recognition paradigm have shown differential modulation of the N400 and LPC by multiple repetitions both in children and adults (Van Strien, Glimmerveen et al., 2009; Van Strien et al., 2005). We hypothesized that older children would recognize more faces correctly compared to younger children, and that older children would rely more on conscious recollection (cf. Cycowicz, 2000). We therefore expected larger early ERP (N2, N400) old/new and repetition effects in younger children, and larger LPC old/new and repetition effects in older children. 


\section{Study 1 - Children}

\section{Methods}

\section{Participants}

Healthy children from regular primary schools were screened for handedness. Handedness was assessed with a 10-item handedness questionnaire (Van Strien, 1992). Only strong right-handed children (right-handed for 9 out of 10 activities) were included. Exclusion criteria were psychoactive medication and history of neurological disorder (as indicated by the parents). All participants had normal or corrected to normal vision. The final sample included 36 younger children ( 8 and 9 years old; 18 males; $M=107.6$ months, $\mathrm{SD}=6.6$ ) and 36 older children (11 and 12 years old; 14 males, $M=143.1$ months, $S D=6.9)$. To avoid the other-race effect for face recognition (e.g., Kelly et al., 2007), all children were Caucasian. The educational level of the participants' parents did not differ between the age groups. All parents provided written informed consent. Preceding the EEG session, information about the procedure was given to the children. Children received a small present, such as a key ring or a set of pencils, for their participation. The study received approval from the Rotterdam Medical Ethics Review Committee.

\section{Stimuli}

For the continuous face recognition task, 90 different faces (45 female) were selected from four different online databases: NimStim Set of Facial Expressions (Tottenham et al., 2009, 14 faces, 5 female), Nottingham Scans (http://pics.psych.stir.ac.uk, 6 faces, all female), Aberdeen Faces (http://pics.psych.stir.ac.uk, 14 faces, 7 female), and AR Face Database (Martinez \& Benavente, 1998, 56 faces, 27 female). The photographs depicted white Caucasian adults in a neutral, frontal pose. All pictures were resized to $200 \times 250$ pixels and converted to grayscale. If necessary, the pictures were edited to have a white background. Thirty different face stimuli (15 female) were presented six times each, and were intermixed with 60 other faces (30 female) that were presented only once to elicit supplementary 'new' responses. Each trial therefore contained either a new face (New), or a first to fifth repetition (R1, R2, R3, R4, R5). The total number of trials equaled 240. The face stimuli were presented in semi-random order, with at least three intervening stimuli between the successive presentations of a particular face. 


\section{Procedure}

Study 1 was part of a larger study concerning the developmental aspects of recognition memory in school-age children. The EEG session took place in a separate room at school and started with a word recognition task, which took approximately 17 minutes (not reported here, see Van Strien, Glimmerveen et al., 2009). After a break, the face recognition task was administered.

The face stimuli were displayed in the center of a black background using a Dell XPS M170 laptop with a 17 inch TFT active matrix screen. The children were seated in a comfortable office chair at a distance of approximately $50 \mathrm{~cm}$ from the screen, with the face stimuli subtending approximately $7.8 \times 9.8^{\circ}$ of visual angle.

The sequence for each trial was: (1) the presentation of a fixation cross in the center of the computer screen with a variable duration of 400 to $600 \mathrm{~ms}$ to reduce time-locked EEG phase or expectancy effects, (2) the $500 \mathrm{~ms}$ presentation of the face in the center of the screen, (3) the $1200 \mathrm{~ms}$ presentation of the fixation cross, and (4) a $1500 \mathrm{~ms}$ inter-trial interval (a black screen). The maximum response time was set at $2500 \mathrm{~ms}$.

The participants were instructed to focus on the fixation cross and to give an 'old' or 'new' response as soon as they recognized the old and new faces that appeared on the screen. It was explained that a 'new' response was correct when a face was presented for the first time, while an 'old' response was correct when a face was presented for the second through sixth time. Participants responded by pressing with their index fingers one of two buttons located at the left and the right side of the screen. The assignment of 'old' and 'new' responses to the left and right response button was counterbalanced across participants. Response latencies were collected using two small response-button boxes connected to a Serial Response Box (Psychology Software Tools, Pittsburgh, Pennsylvania, USA).

Preceding the experimental run, the participants were presented with a series of 21 practice trials with feedback on their performance at the end of each trial ('correct', 'incorrect', 'too late'). If a participant had less than $80 \%$ correct in the first practice series, a second practice series with 21 trials was started. After the second practice series, the experimental run was started irrespective of the number of correct practice trials (six younger children and six older children did not reach the $80 \%$ criterion after the second practice series). In the practice trials, faces were 
presented that were not used in the experimental run. No feedback was given during the experimental run.

\section{EEG recordings}

EEG activity was recorded with a BioSemi Active-Two system from 64 pin-type active $\mathrm{Ag} / \mathrm{AgCl}$ electrodes mounted in an elastic cap according to the international 10-20 system. Flat-type active electrodes were attached to the left and right mastoids. To measure eye movements, the electrooculogram (EOG) was recorded from four flat-type active electrodes positioned above and beneath the left eye and at the outer canthi of the eyes. An additional active pin-type electrode (CMS - common mode sense) and a passive pin-type electrode (DRL - driven right leg) were used to comprise a feedback loop for amplifier reference. The EEG and EOG signals were digitized with a $512 \mathrm{~Hz}$ sampling rate and 24-bit A/D conversion. Response latencies were recorded online along with the EEG data.

Offline, the EEG signals were referenced to the averaged mastoids ${ }^{1}$ and phase-shift-free filtered with a band pass of .15 Hz to $30 \mathrm{~Hz}$. ERP epochs with an 1100-ms duration were extracted, starting $100 \mathrm{~ms}$ before stimulus onset. Correction for ocular artifacts was done using the Gratton, Coles, and Donchin (1983) algorithm. The ERPs were baseline corrected relative to the mean amplitude of the prestimulus period and were averaged for each participant and each of the six consecutive presentations (new, first repetition to fifth repetition). Epochs with an incorrect response and epochs with a baseline-to-peak amplitude difference larger than $+/-150$ $\mu \mathrm{V}$ on any channel were excluded. The mean number of valid epochs per condition ranged from 20.04 (new faces) to 24.92 (fifth repetition) with a mean across conditions of 22.97 .

\section{Data analyses}

Based on inspection of the ERP waveforms and in accordance with previous research, the anterior N2 was quantified by mean amplitude measures in the 200-275 ms time window (see Guillem et al., 2001), the N400 by mean amplitude measures in the 350-450 ms time window

\footnotetext{
1 Although ERP studies concerning face perception often employ an average reference to obtain lateral N170 face potentials, the present study primarily concerned recognition memory. For comparison with previous extended continuous recognition studies, and because we expected within- and between-group differences in vertically oriented ERP components like the N400 and LPC, we chose an averaged mastoids reference.
} 
(see Van Strien, Langeslag et al., 2009), and the LPC by mean amplitude measures in the 650850 ms time window (see Czernochowski et al., 2005).

The behavioral and EEG data were subjected to analyses of variance (ANOVAs). The factors that were included in each individual ANOVA are indicated in the various results sections below. Note that in this paper the factor 'old/new' refers to the first vs. second presentation (New, $\mathrm{R} 1$ ), the factor 'repetition' refers to the first through fifth repetition (R1 through R5), and the factor 'presentation' refers to the six consecutive presentations of a face (New, R1 through R5). In case of significant effects for the repetition factor, linear and quadratic trends were tested. Where appropriate, F-ratios were tested with Greenhouse-Geisser corrected degrees of freedom. The F-values, uncorrected degrees of freedom, epsilon values and corrected p-values are reported.

Preliminary statistical analyses on both the behavioral and EEG data revealed no readable main or interaction effects for gender. Therefore the age groups were collapsed across boys and girls.

\section{Results}

\section{Behavioral data}

For each level of presentation (New, R1 through R5), we determined the participant's accuracy and mean reaction time across correct trials. Table 1 presents the mean reaction times and mean accuracies (percentages correct responses) for new faces and repetitions, as a function of age group. The reaction-time and accuracy data were analyzed by means of ANOVAs with age group as a factor between subjects and presentation (New, R1 through R5) as a factor within subjects.

For the reaction-time data, we found significant main effects of age group, with older children showing faster responses than younger children, $F(1,70)=5.44, p=.023$ (younger: $M=$ $900 \mathrm{~ms}, S D=201$; older: $M=795 \mathrm{~ms}, S D=182)$, and presentation, $F(5,350)=82.89$, epsilon $=$ $.588, p<.001$. These main effects were qualified by the significant interaction of age group and presentation, $F(5,350)=5.04$, epsilon $=.588, p=.002$, with younger children showing a relatively larger increase in response speed across repetitions than older children (see Table 1). Single comparisons revealed that older children responded faster than younger children to new 
faces $(p=.002)$, first repetitions $(p=.009)$, second repetitions $(p=.012)$, and third repetitions ( $p$ $=.053$ ), but not to fourth and fifth repetitions (both $p$-values > .205) .

For the accuracy data, we found a significant main effect for presentation, $F(5,350)=$ 52.08 , epsilon $=.447, p<.001$, with accuracy increasing across the number of repetitions (see Table 1). When analyzed separately, the accuracy for new faces was significantly larger in older compared to younger children, $F(1,70)=4.80, p=.032$.

To examine whether the age groups differed in response bias, the bias measure $\mathrm{Br}$ was computed as the false alarm rate (across all new words, including distracter words) divided by 1 minus the difference of hit rate (across R1 through R5) and false alarm rate (Snodgrass \& Corwin, 1988). Br scores range from 0 to 1 , with scores above .50 indicating a liberal response strategy, that is, a tendency towards "old" decisions. The mean response bias measures indicated that both younger $(\mathrm{Br}=.75, S D=.15)$ and older $(\mathrm{Br}=.72, S D=.15)$ children exhibited a moderate response tendency towards "old" decisions. No significant age difference was found for $\mathrm{Br}(F<1)$.

\section{ERP old/new effects (R1 vs. new)}

For each age group, the grand-average ERPs at selected electrodes for 'new' vs. 'old' (= first repetition) faces are depicted in Figure 1. To analyze the N2, N400, and LPC old/new effects, individual electrodes were clustered in six regional averages arranged in a three-by-two layout with a left frontal (AF3, F5, F3, F1), a right frontal (AF4, F6, F4, F2), a left temporal (FT7, FC5, T7, C5), a right temporal (FT8, FC6, T8, C6), a left central (FC3, FC1, C3, C1), and a right central cluster (FC3, FC1, C3, C1). Individual ANOVAs were conducted for each ERP component, with age group as between-subjects factor and old/new (R1 vs. New), location (frontal, temporal, central), and laterality (left, right) as within-subjects factors.

$N 2$. The topographic distribution of the N2 old/new effect is given in Figure 2A. From this figure, it can be seen that younger children in particular showed a widespread $\mathrm{N} 2 \mathrm{old} / \mathrm{new}$ effect across bilateral central and frontal regions. We found a significant main effect of old/new, $F(1,70)=12.83, p=.001$, with smaller negative $\mathrm{N} 2$ peaks for 'old' $(M=-3.6 \mu \mathrm{V}, S D=5.0)$ than for 'new' faces $(M=-5.4 \mu \mathrm{V}, S D=6.0)$. There was no main effect of age group $(F<.5)$, but there was a significant interaction of age group and old/new, $F(1,70)=7.21, p=.009$. The old/new effect appeared to be significant for younger children (new: $M=-6.3 \mu \mathrm{V}, S D=6.4$; old: 
$M=-3.1 \mu \mathrm{V}, S D=5.0 ; p<.001$ ) but not for older children (new: $M=-4.5 \mu \mathrm{V}, S D=5.7$; old: $M$ $=-4.1 \mu \mathrm{V}, S D=5.1 ; p=.449)$. These effects were further qualified by a significant interaction of age group, old/new, location, and laterality, $F(2,140)=6.47$, epsilon $=.901, p=.003$. From Figure $2 \mathrm{~B}$, it can be seen that the $\mathrm{N} 2 \mathrm{old} / \mathrm{new}$ effect was much larger at all regions in younger children, and that in the younger children the old/new effect tended to be larger at right than at left temporal electrodes $(p=.058)$.

N400. From Figure 2C, it can be seen that younger children exhibited a larger N400 old/new effect than older children at bilateral central and fronto-central regions. There was a significant main effect for age group, $F(1,70)=8.76, p=.004$, with younger children $(M=-15.6$ $\mu \mathrm{V}, S D=5.4)$ showing larger negative $\mathrm{N} 400$ amplitudes than older children $(M=-11.6 \mu \mathrm{V}, S D=$ 6.2). The main old/new effect was also significant, $F(1,70)=21.73, p<.001$, with larger negative N400 amplitudes for 'new' faces $(M=-14.8 \mu \mathrm{V}, S D=6.6)$ than for 'old' faces $(M=-12.3 \mu \mathrm{V}$, $S D=5.9$ ). In addition, the interaction of age group and old/new was significant ${ }^{2}, F(1,70)=7.16$, $p=.009$. Follow-up tests revealed that the N400 old/new effect was significant for younger children (new: $M=-17.6 \mu \mathrm{V}, S D=6.6$; old: $M=-13.6 \mu \mathrm{V}, S D=5.2 ; p<.001$ ) but not for older children (new: $M=-12.1 \mu \mathrm{V}, S D=6.6$; old: $M=-11.0 \mu \mathrm{V}, S D=6.5 ; p=.133$ ).

$L P C$. The ANOVA on the LPC data yielded no significant main effects or interactions for age group or old/new.

\section{ERP repetition effects $(R 1$ through $R 5)$}

Figure 3A displays the extended repetition effect (R1 to R5) at central sites for younger and older children. To analyze the N2, N400, and LPC extended repetition effects, individual ANOVAs were conducted for each ERP component at the central clusters with age group as betweensubjects factor, and repetition (R1 through R5) and laterality (left, right) as within-subjects factors.

$N 2$. For the N2, we found a significant main effect for repetition, $F(4,280)=13.34$ epsilon=.932, $p<.001$. Both the linear contrast, $F(1,70)=27.45, p<.001$, and the quadratic contrast, $F(1,70)=16.07, p<.001$, were significant. Fig 3B displays the N2 repetition effect,

\footnotetext{
${ }^{2}$ When we controlled for possible age differences in skull thickness and bone conductivity by means of converting the old/new amplitudes to within-age-group Z-scores, thus cancelling the main age group effect, the interactions of age group and old/new remained significant for both $\mathrm{N} 2, \mathrm{~F}(1,70)=6.50, \mathrm{p}=.013$, and $\mathrm{N} 400, \mathrm{~F}(1,70)=7.73, \mathrm{p}=$ .007 .
} 
with diminishing N2 negativity across the first four repetitions. No interaction of age group and repetition was found $(p=.575)$.

N400. For the N400, the repetition effect was significant, $F(4,280)=13.35$, epsilon $=$ $.947, p<.001$, as was the linear contrast, $F(1,70)=45.41, p<.001$. The N400 negative amplitude decreased with the increasing number of repetitions. Further, there was a significant interaction of age group and repetition, $F(4,280)=2.97$, epsilon $=.947, p=.022$. This interaction is depicted in Figure 3C. From this picture, it can be seen that the younger children exhibited a steeper decline in N400 negativity across the five repetitions than the older children did. Single comparisons revealed larger N400 amplitudes for younger vs. older children at R1 $(p=.030)$ and R4 ( $p=$ .055). To explore a possible association between the N400 and the behavioral results, we correlated the $\mathrm{N} 400$ repetition effect (R5 minus R1) with RT and with accuracy (R5 minus R1). For neither younger nor older children, significant correlations were found.

$L P C$. For the LPC, no main or interaction effects for age group or repetition were found.

\section{Discussion}

The aim of study 1 was to examine developmental changes in face recognition memory in 8- to 9year-old and 11- to 12-year-old children. We used an extended continuous face recognition paradigm to assess developmental changes in behavioral performances and in early (N2, N400) and late positive (LPC) components of the ERP old/new and extended repetition effects.

\section{Childrens' behavioral data}

Across repetitions, both age groups displayed increasing response speed and accuracy, which indicates better encoding and retrieval after multiple repetitions. Better initial encoding and retrieval in older than in younger children was reflected by shorter reaction times for correct 'old' or 'new' responses. At the outset, younger children were slower, but after two repetitions they started to approach the response speed of older children. Apparently, after repeated encoding, retrieval becomes faster in younger children and comparable to older children. With regard to accuracy, older children better recognized new faces, but exhibited no differences from younger children across the five repetitions. Older children might show superior recognition of new faces 
because they generally have less difficulty recognizing unfamiliar faces than younger children (e.g., Taylor, Batty, \& Itier, 2004).

Younger and older children both showed comparable response biases $(\mathrm{Br}=.75$ vs. .72$)$ and tended to respond in a moderately liberal direction (i.e., toward 'old' responses). Previous recognition memory research in older adults has suggested that a more liberal response bias is associated with diminished frontal functioning (Huh, Kramer, Gazzaley, \& Delis, 2006). It could be hypothesized that a liberal response bias in children is a similar consequence of immature frontal functioning. However, it may also be the result of task-specific demands, because with words both groups of children exhibited a much smaller tendency toward 'old' decisions $(\mathrm{Br}=$ .61, see Van Strien, Glimmerveen et al., 2009) than with faces.

\section{Childrens' ERP old/new effects}

In younger, but not in older children, the $\mathrm{N} 2$ was more negative going for new compared to old (i.e., first repetition) presentations at frontocentral sites. Previous research has suggested that in adults, the frontocentral N2 may reflect a mismatch between stimulus input and existing representations (Folstein \& Van Petten, 2008). In 18-month-old children, a parietal N2 peaking at $250 \mathrm{~ms}$ was larger (more negative) in response to unfamiliar than in response to familiar toys (Carver, Meltzoff, \& Dawson, 2006). In general, novel stimuli (i.e., unfamiliar faces) will elicit a larger N2 than known stimuli. The larger N2 old/new effect in younger children may therefore be related to their difficulty to process unfamiliar faces. In these younger children, the N2 old/new effect tended to be larger at right than at left temporal regions, which might reflect righthemispheric specialization in face processing (e.g., Schweinberger, Pfutze, \& Sommer, 1995).

In addition, younger children displayed larger N400 amplitudes and larger N400 old/new effects at frontal and central regions than older children. The larger N400 amplitudes suggest the allocation of more resources for face recognition in younger compared to older children. Consistent with the present influence of age on the N400 amplitude, Itier and Taylor (2004) found a general age effect in the 300-600 ms time window in children from 8 to 16 years of age, with less negative amplitudes with increasing age. These authors further found frontal N400 old/new effects for faces in all age-groups but reported no interaction of age and repetition. This latter outcome may be a consequence of the repetition lags chosen in the Itier and Taylor study. The faces were repeated immediately after the first presentation (0-lag) or after one intervening 
face (1-lag). With these short lags, the involvement of a general working-memory system may have been larger than with longer lags as used in the present study.

Younger and older children did not demonstrate a LPC old/new effect. The LPC old/new effect is thought to reflect more conscious recollection. Apparently the children based their old/new decisions on more or less automatic priming processes (e.g., template matching) rather than on conscious recollection. This would be in accordance with research showing that children rely more on early familiarity-related processing than on recollection (e.g., Ofen et al., 2007). This reliance on more automatic recognition appears to be specific for face recognition, because with words, both age groups exhibited a clear LPC old/new effect suggesting that recollection plays a substantial role in word recognition memory of both younger and older children. (Van Strien, Glimmerveen et al., 2009). With line drawings, Czernochowski et al. (2005) also found later parietal old/new effects in younger and older children.

\section{Childrens' repetition effects}

At left and right central clusters, we found robust repetition effects (R1 through R5) for both the $\mathrm{N} 2$ and N400. The decline of the N2 negativity upon repeated presentations may reflect the diminishing novelty of the face stimuli. The N400 repetition effect differed between age groups. Younger children showed a steeper decline in N400 negativity over multiple face repetitions than

older children, which seems to parallel the age differences in response speed. However, we found no significant correlations between the $\mathrm{N} 400$ repetition effect and the behavioral data. The repetition effects for the early N2 and N400 ERP components suggest that in children face recognition is based on more automatic processing. The larger N400 repetition effect in younger children when compared to older children indicates a gradual development of these automatic memory processes, with less allocation of resources for face recognition with increasing age.

For the 650-850 ms time window (LPC) we found no repetition effects. This result suggests that the later and more conscious recollection processes do not play a substantial role in face recognition in children. It was expected that on repeated presentations, a face would be recollected more consciously, which would be reflected by a greater LPC repetition effect, especially in older children. With the present continuous face recognition task, the earlier automatic recognition processes apparently suffice and no further memory updating takes place. 


\section{Study 2 - Adults}

To provide a context for the outcome of the younger and older children, we administered the same continuous face-recognition task to a sample of adults. We expected N2 and N400 old/new effects and robust LPC repetition effects in adults (cf. Van Strien et al., 2005).

\section{Method}

\section{Participants}

Participants were 20 healthy students (10 men, 10 women). They had a mean age of 22.7 years (range 20-25 years) and had normal or corrected-to-normal vision. All participants were right-handers by self-report. They participated in the experiment either as volunteers or for course credits, and provided written informed consent.

\section{Materials and Procedure}

Study 2 was performed in our psychology lab. Participants were seated in a sound attenuated, and dimly-lit chamber at a distance of approximately $120 \mathrm{~cm}$ in front of the screen. The face stimuli (approximately $3.8 \times 4.7^{\circ}$ of visual angle) were displayed on a black background using a 20-inch high resolution PC monitor. Instructions, trial sequence, and practice trials were identical to Study 1.

\section{EEG recordings}

EEG activity was recorded with a BioSemi Active-Two system from 32 pin-type active $\mathrm{Ag} / \mathrm{AgCl}$ electrodes mounted in an elastic cap. Further EEG recording and preprocessing characteristics such as filtering and ocular correction were identical to Study 1. Epochs with an incorrect response and epochs with a baseline-to-peak amplitude difference larger than $+/-100 \mu \mathrm{V}$ on any channel were excluded. The mean number of valid epochs per condition ranged from 20.75 (new faces) to 28.95 (fifth repetition) with a mean across conditions of 26.51 . 


\section{Data analyses}

Similar to Study 1, the anterior N2 was quantified by mean amplitude measures for the 200-275 ms time window and the N400 by mean amplitude measures for the 350-450 ms time window. Inspection of the data revealed that the LPC was peaking earlier in adults. For this reason, the LPC was quantified by mean amplitude measures for the 450-600 ms time window. To evaluate the N2, N400 and LPC components, individual electrodes were clustered in six regions, with a left frontal (F3, F7, FC5), midline frontal (FC1, Fz, FC2), right frontal (F4, F8, FC6), left parietal (P3, P7, CP5), midline parietal (CP1, Pz, CP2), and right parietal (P4, P8,CP6) cluster.

\section{Results}

\section{Behavioral data}

For each presentation (New, R1 through R5), the participant's accuracy and mean response latency across correct trials were determined. The accuracy and latency data were analyzed by means of separate ANOVAs, with presentation (New, R1 through R5) as withinsubjects factor.

In Table 2, the mean latencies and percentages correct responses across all participants are shown as a function of presentation. The presentation effect was significant for both accuracy, $F(5,95)=41.80$, epsilon $=.410, p<.001$, and latency, $F(5,95)=39.30$, epsilon $=.445, p<.001$. The accuracy was significantly higher for new faces than for first repetitions $(\mathrm{R} 1), F(1,19)=$ 21.26, $p<.001$. The mean response bias $(\mathrm{Br})$ equaled .65 , indicating a somewhat liberal response tendency towards "old" decisions.

\section{ERP old/new effects (R1 vs. new)}

Figure 4A displays the old/new effect at the lateral frontal clusters. To analyze the old/new effects, the N2, N400 and LPC mean amplitude measures were subjected to separate ANOVAs for each ERP component with caudality (frontal, parietal), laterality (left, midline, right), and old/new (R1 vs. New) as within-subjects factors.

$N 2$. For the N2, a main old/new effect was found, $F(1,19)=5.38, p=.032$, with the N2 area measure being more negative for 'new' $(M=-.32 \mu \mathrm{V}, S D=4.28)$ than for 'old' $(M=.80$ 
$\mu \mathrm{V}, S D=4.54)$ items. No significant topographic differences were found for the $\mathrm{N} 2 \mathrm{old} / \mathrm{new}$ effect.

N400. For the N400, the ANOVA demonstrated a significant old/new effect, $F(1,19)=$ $5.24, p=.034$. The $\mathrm{N} 400$ area measure was more negative for 'new' faces $(M=-.01 \mu \mathrm{V}, S D=$ 3.11) than for 'old' faces $(M=1.36 \mu \mathrm{V}, S D=3.46)$. The topographic distribution of the $\mathrm{N} 400$ old/new effect, with the largest effects at left and right frontal clusters was reflected in a significant interaction of the old/new effect, caudality, and laterality, $F(2,38)=5.18$, epsilon $=$ $.933, p=.012$ (see Figure 4B).

LPC. Neither the main LPC old/new effect nor the interactions of old/new and topography were significant (all $p$-values $>.33$ ).

\section{$E R P$ repetition effects ( $R 1$ through $R 5)$}

Figure 4C displays the repetition effect at the midline parietal cluster. To analyze the extended repetition effects, the ERP measures were subjected to separate ANOVAs for each component with caudality (frontal, parietal), laterality (left, midline, right), and repetition (R1, R2, R3, R4, R5) as within-subjects factors.

$N 2$. The $\mathrm{N} 2$ repetition effect was significant, $F(4,76)=2.91$, epsilon $=.943, p=.030$ (linear: $F(1,19)=12.07, p=.003$; quadratic: $p=.186)$. The $\mathrm{N} 2$ amplitude became less negative upon the increasing number of repetitions. In addition, the interaction of repetition and laterality was significant, $F(8,152)=2.52$, epsilon $=.689, p=.029$, with the repetition effect being larger at midline clusters $(\mathrm{R} 5-\mathrm{R} 1=1.62 \mu \mathrm{V})$ than at left $(\mathrm{R} 5-\mathrm{R} 1=.95 \mu \mathrm{V})$ or right $(\mathrm{R} 5-\mathrm{R} 1=.41 \mu \mathrm{V})$ clusters (linear trends: left vs. midline: $p=.112$; right vs. midline: $p=.018$; left vs. right: $p=$ $.454)$.

N400. For the N400, no significant repetition effects were found.

$L P C$. For the LPC, there was a significant overall repetition effect, $F(4,76)=7.27$, epsilon $=.767, p<.001$ (linear: $F(1,19)=15.75, p<.001$; quadratic, $F<.01$ ). The LPC became more positive, upon the increasing number of repetitions. The topographic differences for the LPC repetition effect were also significant as indicated by the interaction of repetition and caudality, $F(4,76)=3.89$, epsilon $=.719, p=.015$. Inspection of the data revealed that linear trends were larger at parietal regions compared to frontal regions $(p=.005$; see voltage distribution map in Fig. 4D). 


\section{Discussion}

In study 2, we examined an adult sample to have a background for the developmental findings regarding the ERP old/new and repetiton effects with extended continuous face recognition. Here we first discuss the outcome for the adults. In the general discussion, we compare the results of the children with those of the adults.

Adults exhibited a higher accuracy for new words than for first repetitions. With continuous word recognition, we found a similar behavioral outcome (Van Strien et al., 2005). This suggests that in adults, new items are more easily evaluated than old ones at R1, irrespective of stimulus type (words or faces). Across multiple repetitions, accuracy increased and response latencies decreased, which indicates improved encoding and retrieval.

The present face recognition task elicited both an N2 old/new effect and an N2 repetition effect. The anterior N2 component may reflect detection of novelty or mismatch from a visual template (Folstein \& Van Petten, 2008), with repeated presentations resulting in less novelty or mismatch and hence smaller N2 negativity. In our adult sample, this novelty appears to diminish in a regular fashion from new face presentations to the fifth repetition.

The N400 showed an old/new effect but no repetition effect, whereas the LPC showed a repetition effect but no old/new effect. This dissociation is comparable to the dissociation between the early (N400) old/new effect and the late (LPC) repetition effect found with extended continuous word recognition (Van Strien et al., 2005). The outcome for the present facerecognition task supports a dual-processing model of recognition memory, with the N400 old/new effect reflecting an early and more automatic recognition component and the LPC repetition effect a more graded recollection component that depends on memory strengths.

\section{General discussion}

Inspection of Tables 1 and 2 reveals that children responded slower and less accurate than adults. Although we did not statistically test for performance differences between children and adults (because we carried out two separate studies), it seems reasonable to conclude that children had 
more difficulty with the continuous face recognition task than adults. Adults were less accurate in response to first repetitions (R1) than in response to new faces. Younger children tended to demonstrate an opposite pattern (less accuracy for new faces compared to R1, $p=.073$ ) while older children did not differ in accuracy between new faces and R1 $(p=.546)$. With extended word recognition, both children (Van Strien, Glimmerveen et al., 2009) and adults (Hagenbeek et al., 2007; Van Strien et al., 2005) exhibited lower accuracies and longer latencies in response to $\mathrm{R} 1$ than in response to new words. This suggests that new words are more easily evaluated than old words at R1 by all age groups. With faces, children, and younger children in particular, appear to have more difficulty with new items than with R1 items, which is in keeping with their difficulty to recognize unfamiliar faces (Taylor et al., 2004). Note that in comparison with children, the adults' accuracy was much better for new faces, but not for R1 faces (see Tables 1 and 2). The lower accuracy for new faces in children is also reflected in their response biases, which are more liberal than in adults.

Younger children and adults exhibited a significant N2 old/new effect, while older children did not. The larger N2 old/new effect in younger compared to older children may be related to the lesser proficiency of younger children to process new, unfamiliar faces. In adults, the N2 old/new effect may reflect more subtle perceptual priming effects. Moreover, both younger and older children showed a N2 repetition effect, as did adult participants. This N2 repetition effect suggests that early perceptual matching and priming processes play a role in face recognition memory in both children and adults.

Younger children and adults also exhibited significant N400 old/new effects, while older children did not. Larger N400 old/new effects in younger compared to older children may be partly caused by the allocation of more resources for processing new faces by younger children. In adults, the N400 old/new effect reflects the typical early recognition component, akin to familiarity. Both younger and older children showed a N400 extended repetition effect, whereas adults did not exhibit such a N400 repetition effect. Instead, adults exhibited a significant linear LPC repetition effect. Together these results suggest that early and more automatic recognition processes play a role in face recognition memory in both children and adults. In children, better face recognition performance upon repeated presentations seems to depend mainly on increased automatic responses, that is, in a more 'priming-like' manner, whereas in adults better face recognition performance is also associated with more conscious recollection. 
The differential development of early and late nonverbal recognition memory processes may depend on task characteristics such as stimulus type (e.g., faces vs. objects) and response demands (e.g. speeded vs. nonspeeded response). For instance, Mecklinger et al. (Mecklinger, Brunnemann, \& Kipp, 2011) found LPC repetition effects in children using line drawings of objects and animals, but only with nonspeeded and not with speeded old/new judgments. In the present research, participants were required to give a response as soon as they recognized the faces as 'old' or 'new'. It could be that these moderately speeded judgments encouraged children to rely on automatic responses rather than on conscious memory processes.

\section{Conclusion}

The N400 extended repetition effect suggest that in children face recognition memory is mediated by early and probably more automatic than conscious recognition processes. The LPC extended repetition effect indicates that in adults face recognition memory is more related to a graded recollection process. The present study clearly demonstrates distinct developmental trajectories for the N400 and LPC old/new and extended repetition effects. 


\section{Acknowledgements}

We thank Marco Hoeksma for his critical reading of the manuscript and helpful comments. We also thank heads, staff, and pupils of De Overkant, Portland, and De Grote Reis in Rhoon, NL, De Gideonschool and De Rehobothschool in Nieuwerkerk aan den IJssel, NL, and De Regenboog in Delft, NL, for their kind cooperation. 


\section{References}

Ally, B. A., \& Budson, A. E. (2007). The worth of pictures: Using high density event-related potentials to understand the memorial power of pictures and the dynamics of recognition memory. NeuroImage, 35, 378-395.

Berman, S., Friedman, D., \& Cramer, M. (1990). A developmental study of event-related potentials during explicit and implicit memory. International Journal of Psychophysiology, 10, 191-197.

Billingsley, R. L., Smith, M. L., \& McAndrews, M. P. (2002). Developmental patterns in priming and familiarity in explicit recollection. Journal of Experimental Child Psychology, 82, 251-277.

Carver, L. J., Meltzoff, A. N., \& Dawson, G. (2006). Event-related potential (ERP) indices of infants' recognition of familiar and unfamiliar objects in two and three dimensions. Developmental Science, 9, 51-62.

Crookes, K., \& McKone, E. (2009). Early maturity of face recognition: No childhood development of holistic processing, novel face encoding, or face-space. Cognition, 111, 219-247.

Curran, T., Tepe, K. L., \& Piatt, C. (2006). ERP explorations of dual processes in recognition memory. In H. D. Zimmer, A. Mecklinger \& U. Lindenberger (Eds.), Handbook of Binding and Memory: Perspectives from Cognitive Neuroscience (pp. 467-492.). Oxford: Oxford University Press.

Cycowicz, Y. M. (2000). Memory development and event-related brain potentials in children. Biological Psychology, 54, 145-174.

Cycowicz, Y. M., Friedman, D., \& Duff, M. (2003). Pictures and their colors: What do children remember? Journal of Cognitive Neuroscience, 15, 759-768.

Cycowicz, Y. M., Friedman, D., Snodgrass, J. G., \& Duff, M. (2001). Recognition and source memory for pictures in children and adults. Neuropsychologia, 39, 255-267.

Czernochowski, D., Mecklinger, A., Johansson, M., \& Brinkmann, M. (2005). Age-related differences in familiarity and recollection: ERP evidence from a recognition memory study in children and young adults. Cognitive Affective \& Behavioral Neuroscience, 5, 417-433. 
De Haan, M., \& Nelson, C. A. (1997). Recognition of the mother's face by six-month-old infants: A neurobehavioral study. Child Development, 68, 187-210.

de Heering, A., Houthuys, S., \& Rossion, B. (2007). Holistic face processing is mature at 4 years of age: Evidence from the composite face effect. Journal of Experimental Child Psychology, 96, 57-70.

Diamond, R., \& Carey, S. (1977). Developmental changes in the representation of faces. Journal of Experimental Child Psychology, 23, 1-22.

Ellis, H. D. (1992). The development of face processing skills Philosophical Transactions of the Royal Society London: Biological Sciences, 335, 105-111.

Folstein, J. R., \& Van Petten, C. (2008). Influence of cognitive control and mismatch on the N2 component of the ERP: a review. Psychophysiology, 45, 152-170.

Gratton, G., Coles, M. G. H., \& Donchin, E. (1983). A new method for off-line removal of ocular artifact. Electroencephalography and Clinical Neurophysiology, 55, 468-484.

Guillem, F., Bicu, M., \& Debruille, J. B. (2001). Dissociating memory processes involved in direct and indirect tests with ERPs to unfamiliar faces. Cognitive Brain Research, 11, 113-125.

Hagenbeek, R. E., Rombouts, S. A. R. B., Veltman, D. J., Van Strien, J. W., Witter, M. P., Scheltens, P., et al. (2007). Nonlinear changes in brain activity during continuous word repetition: An event-related multiparametric functional MR imaging study. American Journal of Neuroradiology, 28, 1715-1721.

Hepworth, S. L., Rovet, J. F., \& Taylor, M. J. (2001). Neurophysiological correlates of verbal and nonverbal short-term memory in children: Repetition of words and faces. Psychophysiology, 38, 594-600.

Huh, T. J., Kramer, J. H., Gazzaley, A., \& Delis, D. C. (2006). Response bias and aging on a recognition memory task. Journal of the International Neuropsychological Society, 12, 17.

Itier, R. J., \& Taylor, M. J. (2004). Face recognition memory and configural processing: A developmental ERP study using upright, inverted, and contrast-reversed faces. Journal of Cognitive Neuroscience, 16, 487-502.

Kelly, D. J., Quinn, P. C., Slater, A. M., Lee, K., Ge, L., \& Pascalis, O. (2007). The other-race effect develops during infancy. Psychological Science, 18, 1084-1089. 
Kuefner, D., de Heering, A., Jacques, C., Palmero-Soler, E., \& Rossion, B. (2009). Early visually evoked electrophysiological responses over the human brain (P1, N170) show stable patterns of face-sensitivity from 4 years to adulthood. Frontiers in Human Neuroscience, 3, 67. doi:10.3389/neuro.3309.3067.2009.

Martinez, A. M., \& Benavente, R. (1998). The AR Face Database: CVC Technical Report \#24, June 1998.

Mecklinger, A., Brunnemann, N., \& Kipp, K. (2011). Two processes for recognition memory in children of early school age: An event-related potential study. Journal of Cognitive Neuroscience, 23, 435-446.

Ofen, N., Kao, Y.-C., Sokol-Hessner, P., Kim, H., Whitfield-Gabrieli, S., \& Gabrieli, J. D. E. (2007). Development of the declarative memory system in the human brain. Nature Neuroscience, 10, 1198-1205.

Rugg, M. D., \& Curran, T. (2007). Event-related potentials and recognition memory. Trends in Cognitive Sciences, 11, 251-257.

Rugg, M. D., Mark, R. E., Walla, P., Schloerscheidt, A. M., Birch, C. S., \& Allan, K. (1998). Dissociation of the neural correlates of implicit and explicit memory. Nature, 392, 595598.

Schweinberger, S. R., Pfutze, E.-M., \& Sommer, W. (1995). Repetition priming and associative priming of face recognition: Evidence from event-related potentials. Journal of Experimental Psychology: Learning, Memory, \& Cognition, 21, 722-736.

Snodgrass, J. G., \& Corwin, J. (1988). Pragmatics of measuring recognition memory: Applications to dementia and amnesia. Journal of Experimental Psychology: General, 117, 34-50.

Taylor, M. J., Batty, M., \& Itier, R. J. (2004). The faces of development: A review of early face processing over childhood. Journal of Cognitive Neuroscience, 16, 1426-1442.

Tottenham, N., Tanaka, J., Leon, A. C., McCarry, T., Nurse, M., Hare, T. A., et al. (2009). The NimStim set of facial expressions: Judgments from untrained research participants. Psychiatry Research, 168, 242-249.

Van Strien, J. W. (1992). Classificatie van links- en rechtshandige proefpersonen [Classification of left- and righthanded research participants]. Nederlands Tijdschrift voor de Psychologie, 47, 88-92. 
Van Strien, J. W., Glimmerveen, J. C., Martens, V. E. G., \& De Bruin, E. A. (2009). Age-related differences in brain activity during extended continuous word recognition in children. Neuroimage, 47, 688-699.

Van Strien, J. W., Hagenbeek, R. E., Stam, C. J., Rombouts, S., \& Barkhof, F. (2005). Changes in brain electrical activity during extended continuous word recognition. Neuroimage, 26, 952-959.

Van Strien, J. W., Langeslag, S. J. E., Strekalova, N. J., Gootjes, L., \& Franken, I. H. A. (2009). Valence interacts with the early ERP old/new effect and arousal with the sustained ERP old/new effect for affective pictures. Brain Research, 1251, 223-235.

Van Strien, J. W., Verkoeijen, P. P. J. L., Van der Meer, N., \& Franken, I. H. A. (2007). Electrophysiological correlates of word repetition spacing: ERP and induced band power old/new effects with massed and spaced repetitions. International Journal of Psychophysiology, 66, 205-214. 
Figure captions

Fig. 1. Grand-average ERPs for younger children $(n=36)$ and older children $(n=36)$ at selected electrodes in response to new words (black line) and first repetition (red line). Negativity is up.

Fig. 2. A: Spherical-spline interpolated scalp distributions of the N2 (200-275 ms) old/new effects ('old' minus 'new') for younger and older children. B: Mean N2 old/new effects as a function of age and location (F: frontal region, $\mathrm{T}$ : temporal region, $\mathrm{C}$ : central region) and hemisphere. C: Spherical-spline interpolated scalp distributions of the N400 (350-450 ms) old/new effects ('old' minus 'new') for younger and older children.

Fig. 3. A: ERP extended repetition effect at central clusters (left and right averaged) for younger and older children (black line $=$ new; red line $=1^{\text {st }}$ repetition; blue line $=2^{\text {nd }}$ repetition, orange line $=5^{\text {th }}$ repetition; for clarity the third and fourth repetition have been omitted from this graph). B: $\mathrm{N} 2$ repetition effect (averaged central clusters) for the total sample of children. C: N400 repetition effect (averaged central clusters) as a function of age group.

Fig. 4. Adult group. A: Grand-average ERPs at the lateral frontal clusters (left and right clusters averaged) for 'new' (black line) and 'old' (red line) faces. B: Spherical-spline interpolated scalp distribution of the N400 old/new effect (old faces minus new faces). C: Grand-average ERPs at the midline parietal cluster for 'new' faces and first through fifth repetitions. D: Spherical-spline interpolated scalp distribution of the N400 repetition effect (fifth minus first repetition). 
Table 1. Mean reaction time (RT) in milliseconds and accuracy (\% correct) for new faces (New) and the five repetitions (R1 to R5) as a function of age group.

\begin{tabular}{|c|c|c|c|c|c|c|}
\hline & \multicolumn{3}{|l|}{$\mathrm{RT}$} & \multicolumn{3}{|l|}{$\%$ correct } \\
\hline & $\begin{array}{l}\text { Younger } \\
\text { children }\end{array}$ & $\begin{array}{l}\text { Older } \\
\text { children }\end{array}$ & $\begin{array}{l}\text { Total } \\
\text { group }\end{array}$ & $\begin{array}{l}\text { Younger } \\
\text { children }\end{array}$ & $\begin{array}{l}\text { Older } \\
\text { children }\end{array}$ & $\begin{array}{l}\text { Total } \\
\text { group }\end{array}$ \\
\hline New & $1046(213)$ & 887 (196) & 967 (218) & $64.4(19.5)$ & $73.8(16.4)$ & $69.1(18.5)$ \\
\hline R1 & 987 (227) & 854 (194) & $920(220)$ & 72.4 (11.7) & $71.9(12.7)$ & $72.2(12.1)$ \\
\hline R2 & 921 (217) & 793 (207) & 857 (220) & $81.7(11.0)$ & $82.2(11.5)$ & $81.9(11.2)$ \\
\hline R3 & $851(208)$ & $760(184)$ & $806(200)$ & $86.3(12.4)$ & $88.2(9.9)$ & $87.3(11.2)$ \\
\hline R4 & $811(218)$ & $751(186)$ & 781 (203) & $84.8(14.2)$ & $90.3(9.0)$ & $87.6(12.1)$ \\
\hline R5 & 783 (207) & $723(190)$ & 753 (199) & 87.9 (11.8) & $90.2(9.2)$ & $89.0(10.6)$ \\
\hline
\end{tabular}

Note. Standard deviations are reported in parentheses. 
Table 2. Mean reaction times (RT) in milliseconds and accuracy (\% correct) for new faces (New) and five repetitions (R1 to R5) in adults.

\begin{tabular}{lll} 
& \multicolumn{1}{l}{ RT } & \% correct \\
& & \\
New & $761(128)$ & $87.7(8.8)$ \\
R1 & $791(102)$ & $69.1(14.4)$ \\
R2 & $716(89)$ & $87.4(8.6)$ \\
R3 & $663(87)$ & $93.7(5.5)$ \\
R4 & $644(80)$ & $95.9(5.5)$ \\
R5 & $615(71)$ & $96.7(3.9)$ \\
-
\end{tabular}

Note. Standard deviations are reported in parentheses. 


\section{Younger children - old/new effect}

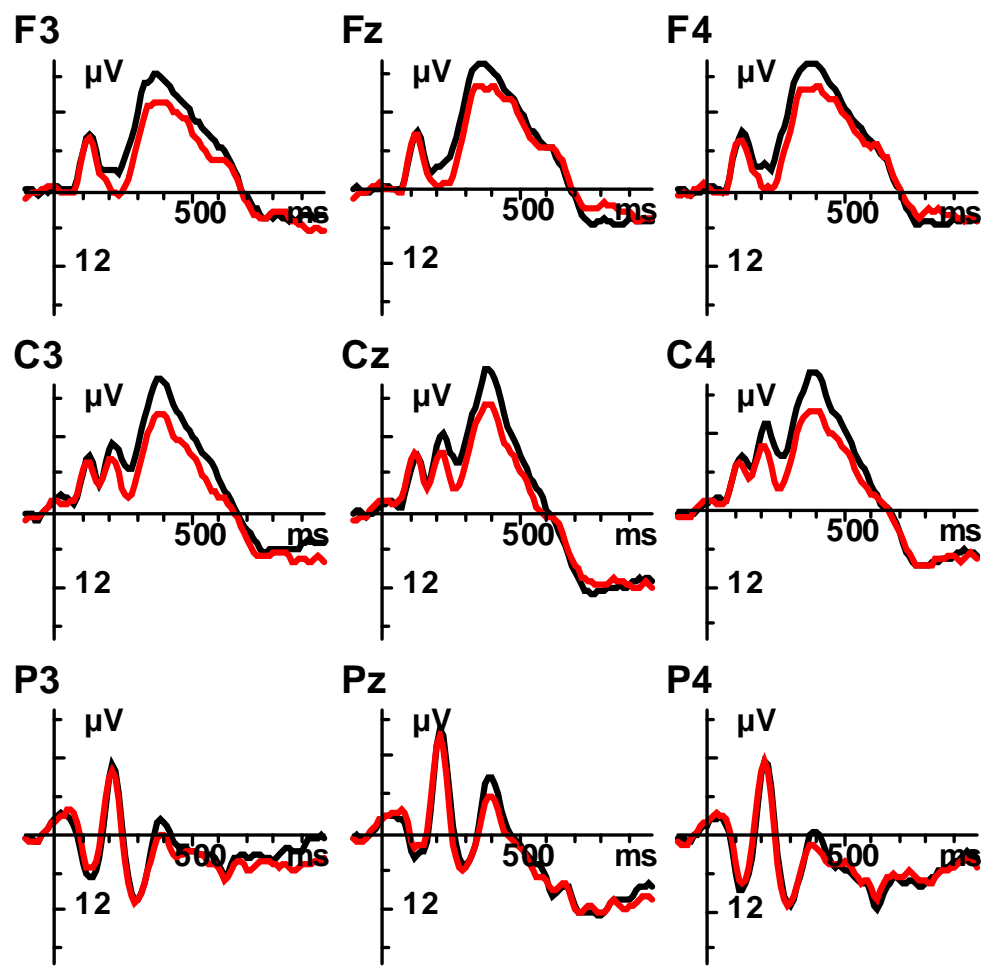

\section{Older children - old/new effect}
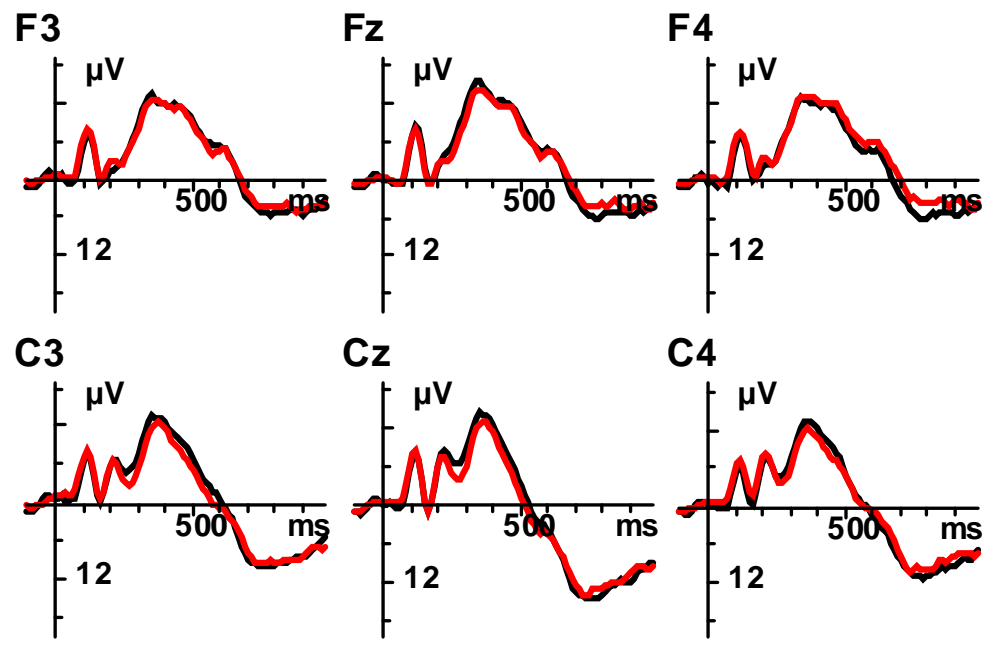

$\mathrm{Cz}$
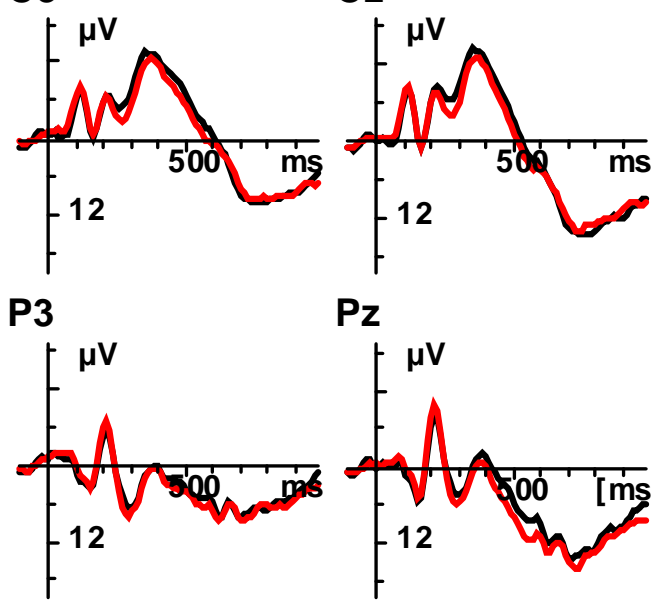

C4
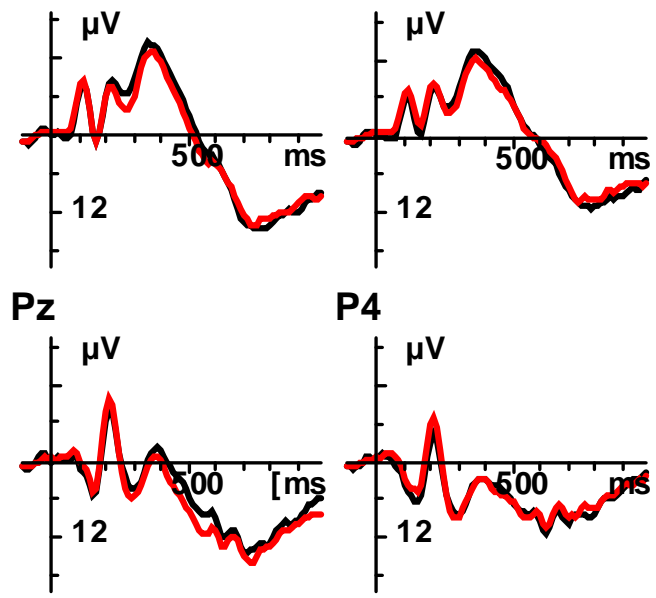
A

$3.5 \mu \mathrm{V}$

$-3.5 \mu \mathrm{V}$

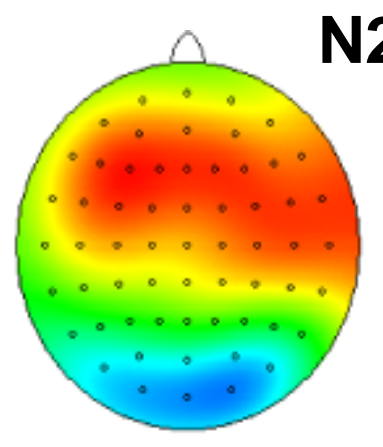

Younger children

old/new

B

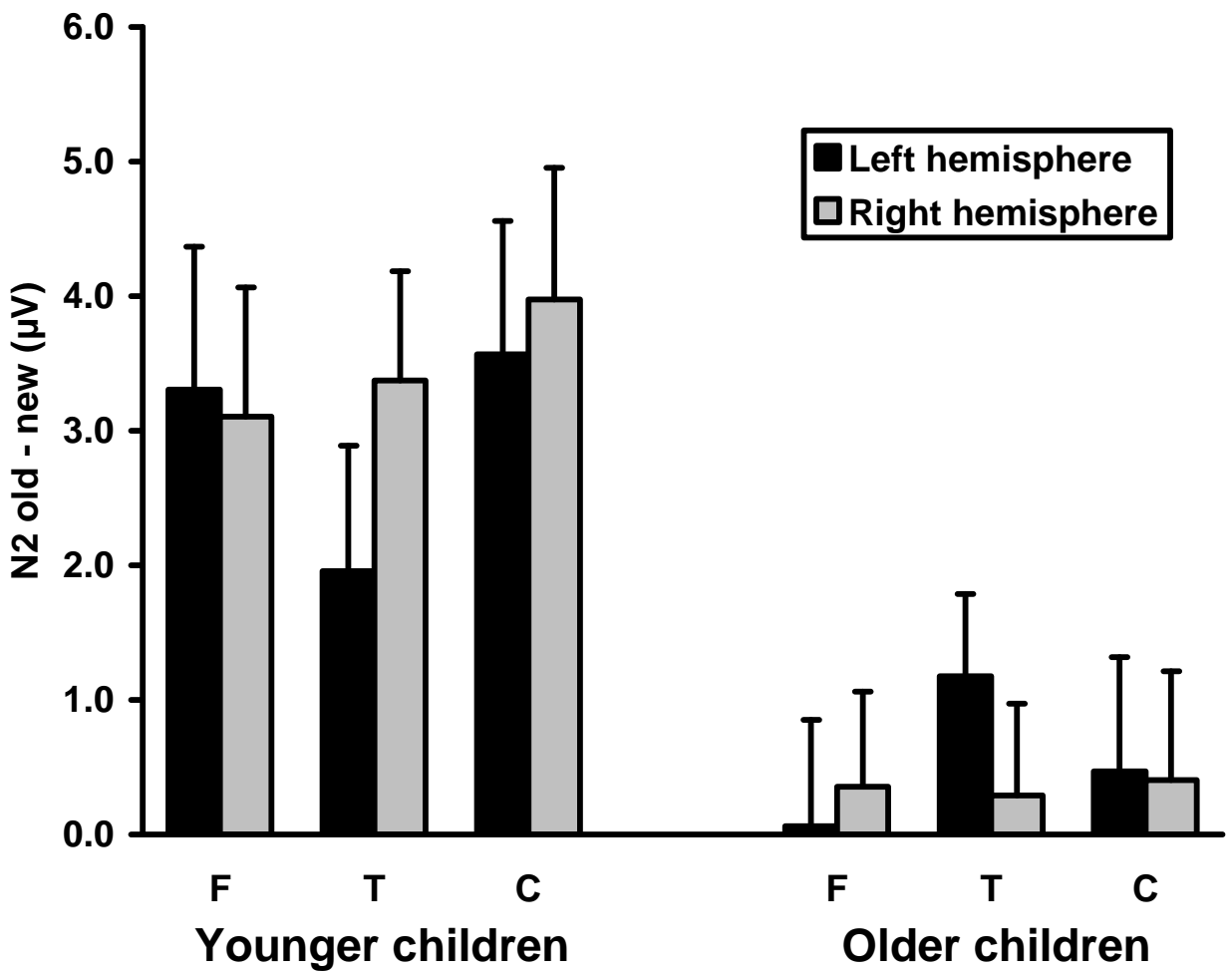

C

$4.9 \mu \mathrm{V}$

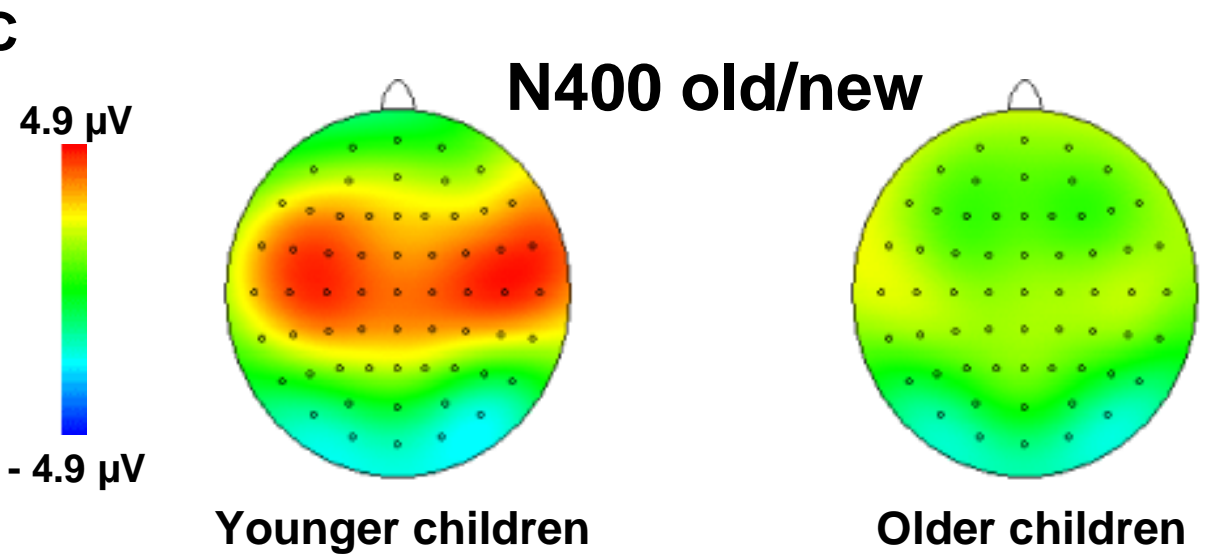

Younger children

Older children 
A

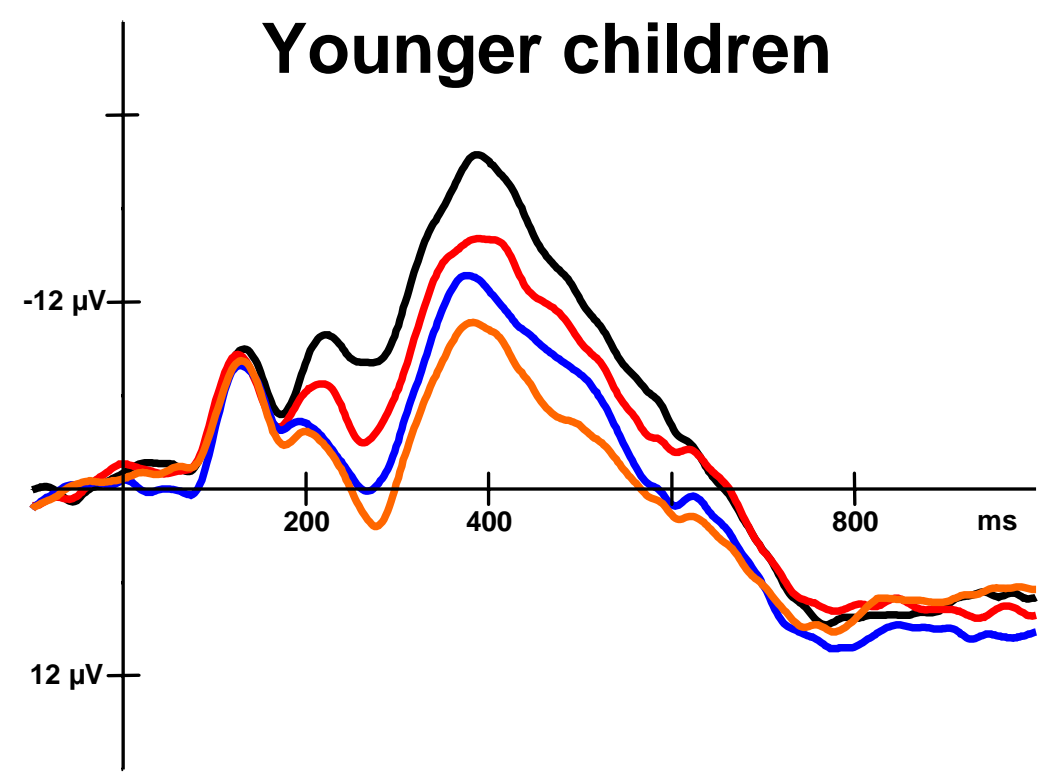

Older children

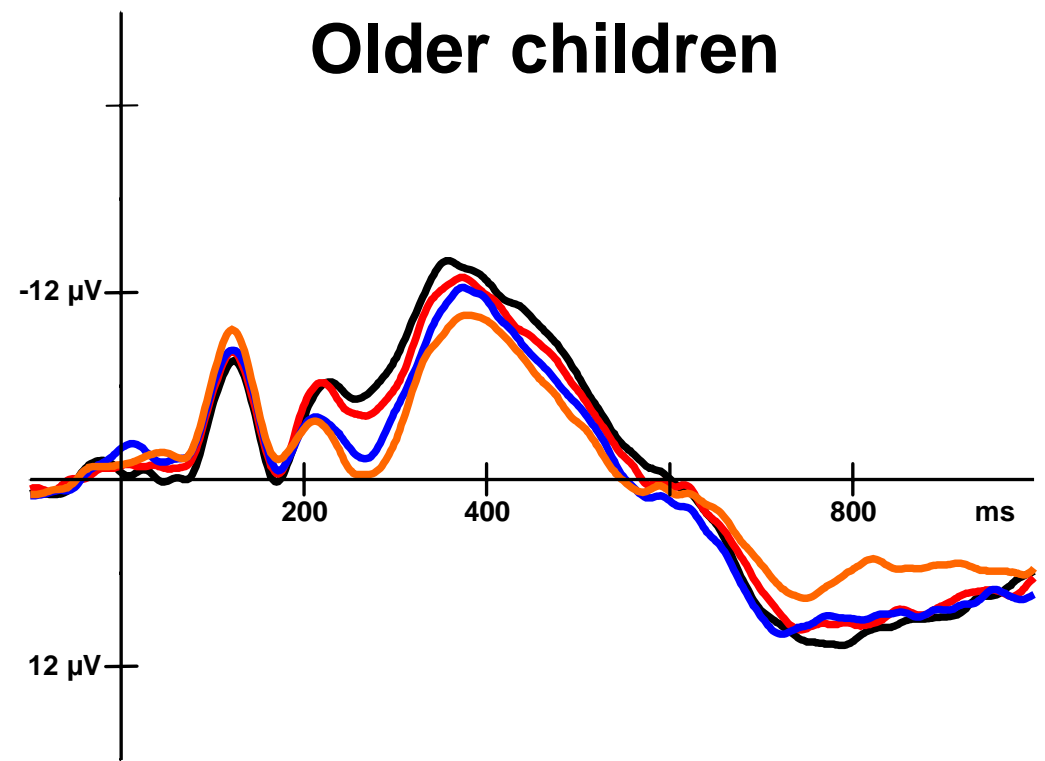

B

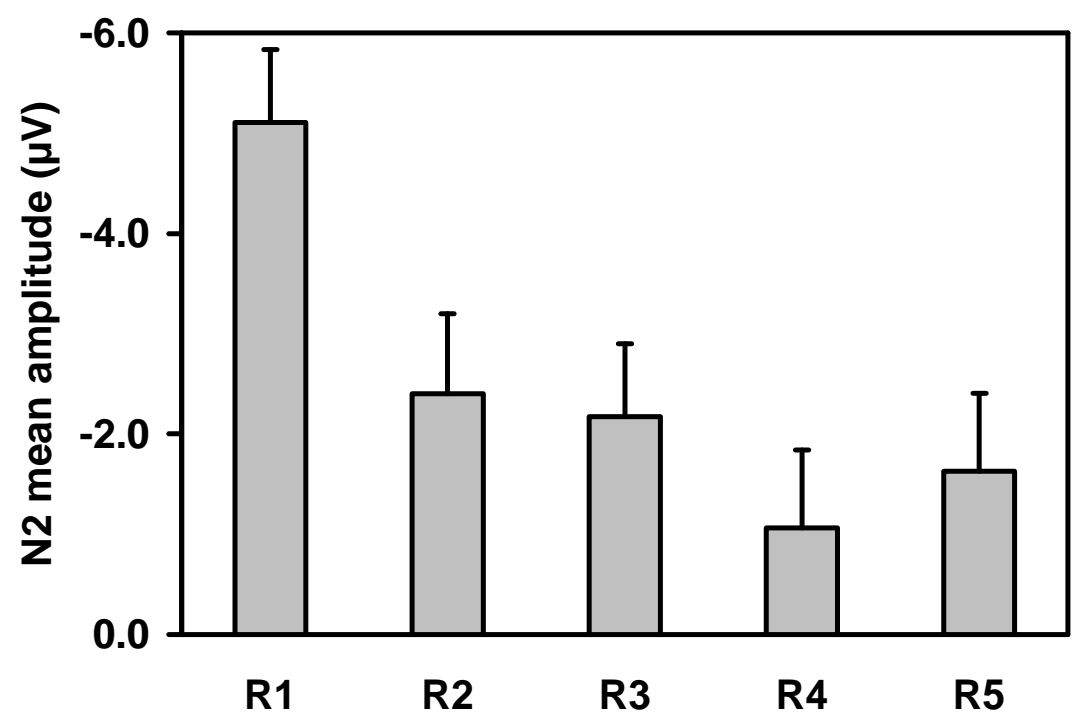

C

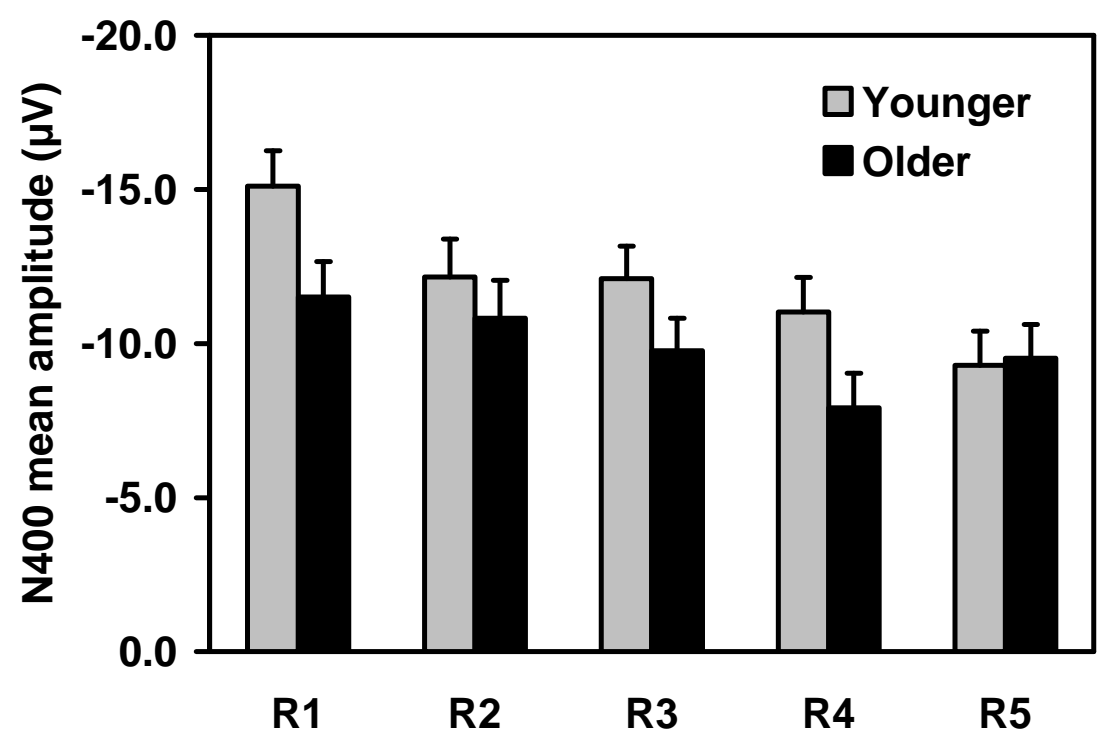




\section{A}

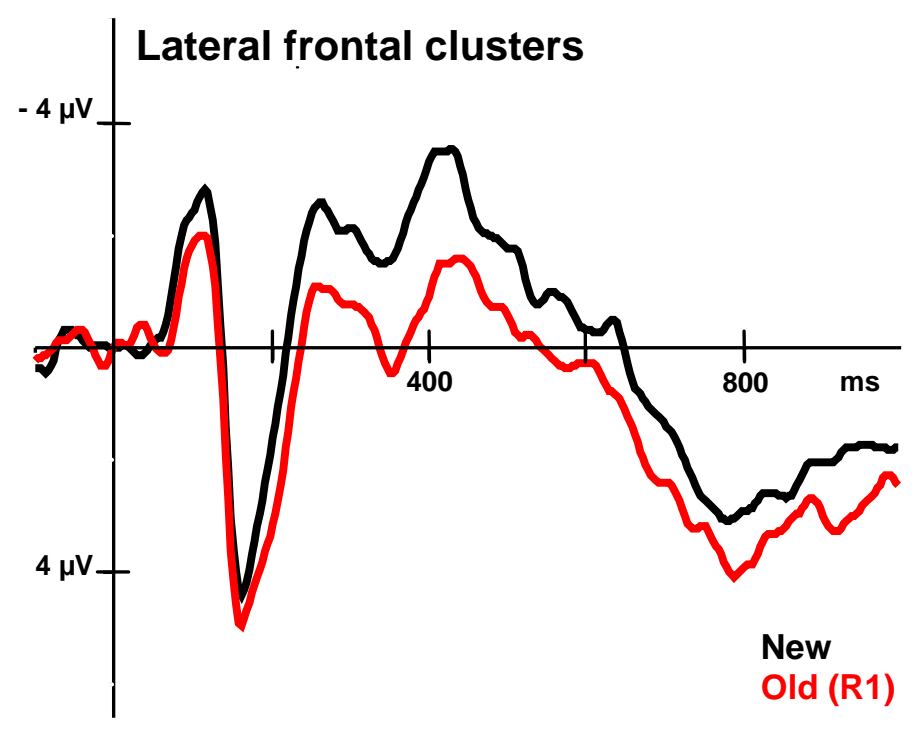

C

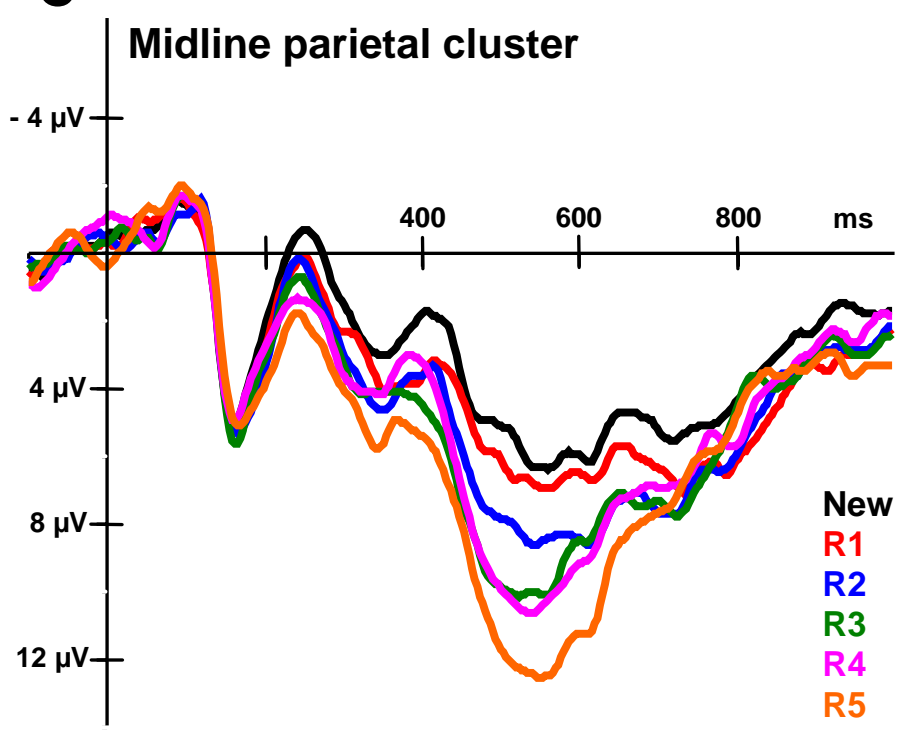

B

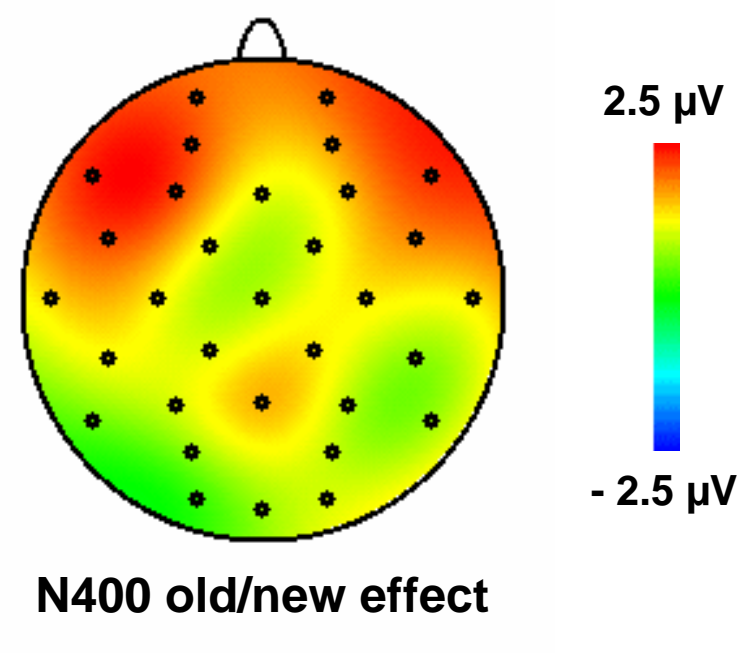

D

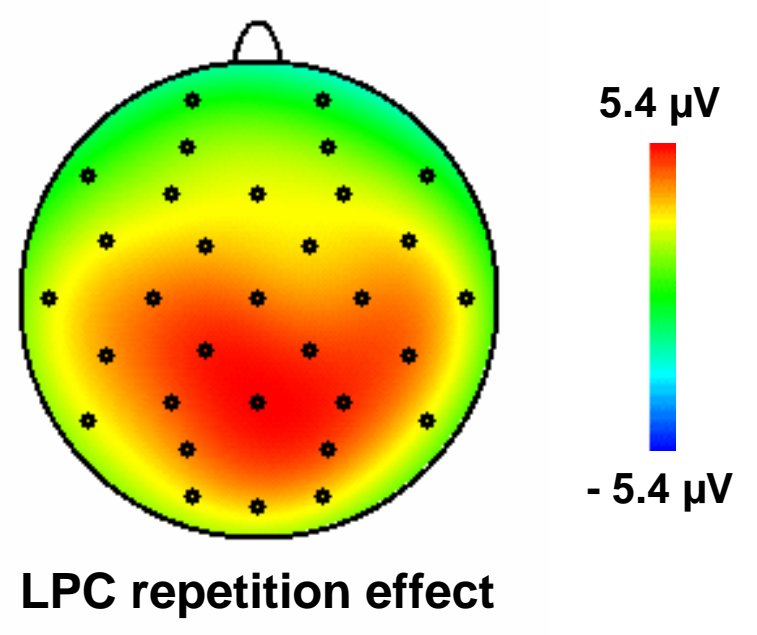

